to pay for agriculture-related research. Although the share of the total budget consumed by the Common Agricultural Policy would fall by some $3 \%$, to about $36 \%$, several observers say that the commission was unable to win support for a more radical transfer of resources from farm subsidies. "The chance to make really big changes to the Common Agricultural Policy has been lost," says Tindemans.

Geoghegan-Quinn says that there are three main pillars to the proposal: excellence in science, meeting 'grand challenges' such as food security, and improving competitiveness.

She says that a much stronger focus will be brought to bear on the grand challenges than before, driven by powerful committees called European Innovation Partnerships. The first such partnership, addressing 'healthy ageing', started earlier this year, and is going well, GeogheganQuinn says, with its board set to select about ten research priorities, and "push forward with them very quickly”.

Geoghegan-Quinn promises "quick decisions" this year on proposals for the management and structure of the European Research Council, the new and widely lauded component of FP7 that backs basic research, which will be released next week by a commission working group.

The commission's proposal also says that future cost overruns on ITER, a giant nuclear-fusion experiment under construction in France, will have to be borne by member states, and will not come from the EU budget or fall on other research programmes.

The budget plan will now be scrutinized by the European Parliament and the Council of Ministers, representing the $27 \mathrm{EU}$ member states, before emerging in final form by 2013. The parliament is widely expected to ask for even more funds for research and innovation, whereas many member states will seek cuts to this and other portions of the commission's proposal.

Jerzy Langer, a physicist at the Polish Academy of Sciences in Warsaw and a close observer of European research policy, says that the outcome so far has been "very good" and indicated "huge determination at the very top" of the commission to support research. He predicted that even such member states as the United Kingdom - which has already said that the overall budget plan is too large - would back the proposed increases for research.

But Luke Georghiou, a policy expert at the University of Manchester, UK, says "it is extremely unlikely that the member states

$\rightarrow$ NATURE.COM

Read more

European stories:

go.nature.com/ptxmzt will agree to anything exceeding this, so we should regard it as a ceiling" on the eventual research budget. .

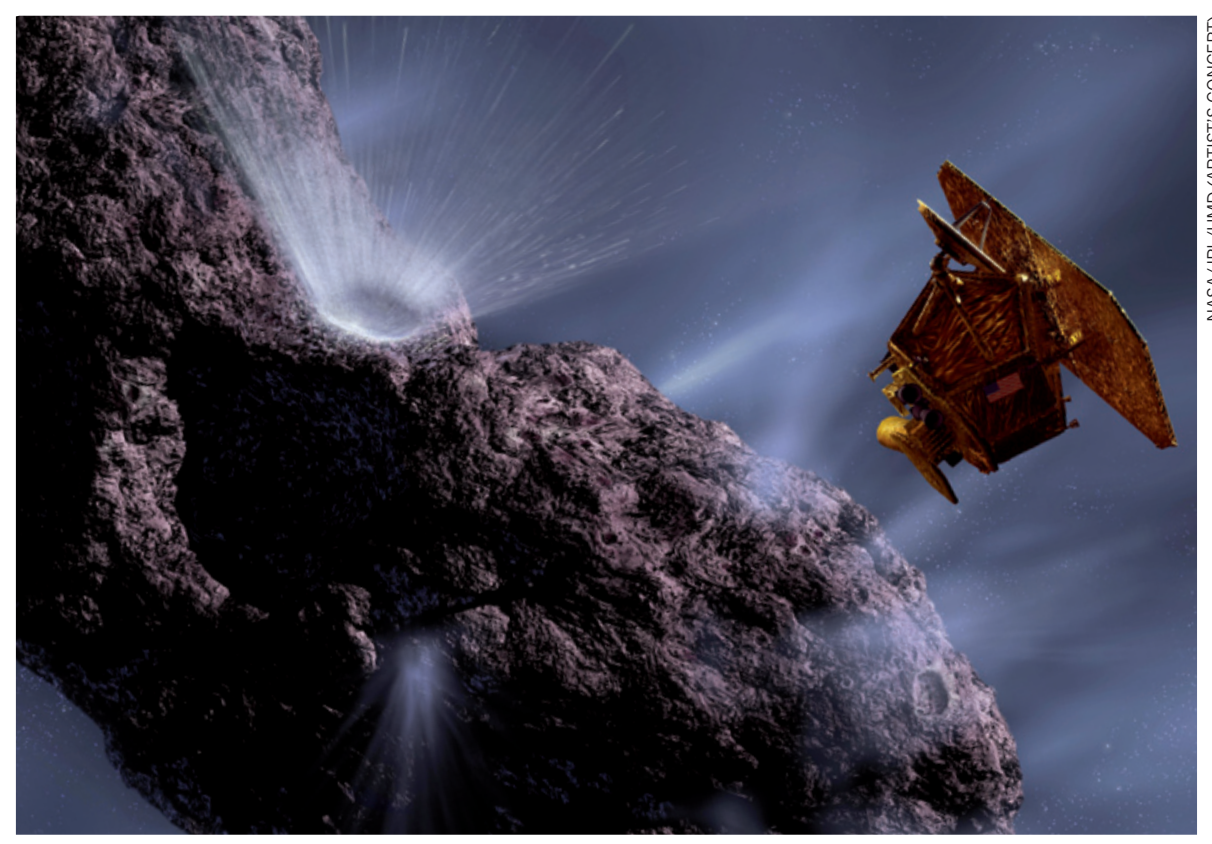

Deep Impact had a novice mission leader, but its comet encounter was a smashing success.

PLANETARY SCIENCE

\title{
NASA faces dearth of mission leaders
}

\section{Experience gap looms large in next generation of principal investigators for Discovery programme.}

\section{BY ERIC HAND}

$\mathrm{W}$

hen NASA invites proposals in 2013 for its next round of low-cost planetary missions, ideas are sure to be plentiful - but not the leaders crucial to the missions' success. That's the conclusion of a demographic analysis that shows that the number of highly qualified principal investigators (PIs) willing or able to take the driver's seat in NASA's Discovery-class missions is dwindling.

"We have to recognize that this is coming and this is a problem," says Susan Niebur, who presented her analysis on 21 June at an international conference on low-cost missions at Johns Hopkins University's Applied Physics Laboratory in Laurel, Maryland. As a cohort of former PIs nears retirement age, Niebur worries that burn out, budget overruns and missed launch windows will be the result if NASA doesn't find a way to get younger scientists the experience they need to step up into mission-leading roles.

Niebur first encountered the dilemma between 2003 and 2006, when she was the NASA official charged with running the fiercely competitive Discovery programme the small, scientist-led planetary probes that are often the most innovative in NASA's repertoire. At that time, she says, she kept getting proposals "from the same guys".

Not that they were unqualified. On the contrary, they were precisely the sort of scientists NASA wanted in charge of spacecraft worth hundreds of millions of dollars - people who knew their science but had also dirtied their hands with instrument hardware and experienced the headaches of building a spacecraft. The problem was that there were so few of them - and they were getting older.

Now an independent consultant based in Silver Spring, Maryland, Niebur has been tracking the situation and says that it is getting worse. By 2015, when the winning proposal is chosen, there will be only 14 potential PIs aged 65 and under who have previously been PIs, deputy PIs or project scientists (see 'Planetary shortfall'). This means that many of the roughly 30 proposals that the Discovery programme attracts at every round will be coming from relative rookies.

Started in 1992, Discovery came to 
PLANETARY SHORTFALL

NASA will have few highly experienced scientists available to be principal investigators (PIs) on low-cost planetary missions. But historically, mission leaders have not had high-level previous experience.

\begin{tabular}{|c|c|c|c|}
\hline \multicolumn{2}{|c|}{ Highest level of previous experience } & \multirow{2}{*}{$\begin{array}{c}2013 \text { competition } \\
\text { (projection)* }^{*} \\
3\end{array}$} & \multirow{2}{*}{$\begin{array}{c}\text { Experience levels of PIs, } \\
\text { 1994-2011 } † \\
0\end{array}$} \\
\hline High & $\mathrm{Pl}$ & & \\
\hline & Deputy PI & 0 & 0 \\
\hline & Project scientist & 11 & 0 \\
\hline \multirow[t]{2}{*}{ Medium } & Instrument PI & 16 & 7 \\
\hline & Deputy project scientist & 11 & 0 \\
\hline \multirow[t]{2}{*}{ Low } & $\begin{array}{l}\text { Co-investigator or } \\
\text { science investigation lead }\end{array}$ & 50 & 6 \\
\hline & No mission experience & All others & 3 \\
\hline
\end{tabular}

*Scientists expected to be 65 or younger at the time of final selection in 2015 .

†Highest-level of previous experience on 16 scientist-led missions, historical or in development.

- embody a new idea: that a space mission could be led by a scientist rather than an engineer. Of the 16 PI-led missions in NASA's history - mainly within Discovery — most have been resounding successes. In some cases, the PIs of those missions stepped into their leadership roles with less experience than NASA anticipated, such as astronomer Michael A'Hearn of the University of Maryland in College Park, who led the Deep Impact mission that pierced a comet's nucleus in 2005.

But that's no reason not to demand moreexperienced PIs, says Alan Stern, NASA's science chief from 2007 to 2008. During his stint at the agency, Stern began looking at Discovery, and found that virtually all the projects in development were bursting their budgets.
Some of the PIs had come straight from the blackboard, and some were like "deer in the headlights", he says. "We're giving them the keys to the kingdom on projects that are worth hundreds of millions of dollars," he adds. "That's an awfully expensive on-the-job training exercise."

Stern implemented strict rules requiring the heads of all PI-led missions to have had experience as a PI, a deputy PI, an instrument PI, a project scientist or a deputy project scientist on a previous mission. The problem with this was that planetary scientists have few chances to build up such experience. Unlike NASA's other science divisions - astrophysics, Earth science and heliophysics - planetary science does not include balloon and sounding-rocket missions that can give younger researchers a chance to lead. The Discovery missions, currently capped at US $\$ 425$ million and launched every few years, are as cheap and as frequent as they come. Stern's rule was seen as too onerous, and it disappeared when he left the agency.

Rather than ruling out PIs with less experience, Niebur says NASA should enlarge the pipeline of eligible candidates. In particular, she wants the agency to require younger deputy PIs on future proposals. But PIs, trying to keep proposals lean, sometimes exclude deputies.

Michael New, the NASA official now in charge of the Discovery competitions, says that of the 28 proposals being considered in the latest round, which began in 2010, 19 include a deputy PI. However, he says, the deputies are on average the same age as the PIs - suggesting that the demographic problem is not going away.

Nor is it safe to assume that deputies will want to take on the notoriously gruelling task of being a PI. In her analysis, Niebur found that of all the PIs, deputy PIs, project scientists and deputy project scientists on all NASA planetary missions since 1977, none went on to lead another mission as a PI.

That's not too surprising, says Bruce Jakosky at the University of Colorado in Boulder, the PI for the Mars Atmosphere and Volatile Evolution Mission (MAVEN), which was selected in 2008 as the winner of NASA's Mars Scout competition - a programme similar to Discovery. It's just too much work. "I have the heart for MAVEN," he says, "but not for another one."

Spain's ship comes in

\section{Globe-trotting expedition hopes to prove the value of old-fashioned scientific seafaring.}

\section{BY LUCAS LAURSEN}

$\mathrm{I}$ $\mathrm{n}$ the age of networked buoys and remotesensing satellites, a global oceanographic cruise might sound like a relic from the golden era of exploration.

But the seven-month trek of Spain's BIO Hespérides, which concludes next week when it docks in Cartagena, aims to deliver a global, comprehensive portrait of the ocean and how it is changing that the project's backers say could not be assembled in any other way.

The Malaspina expedition, organized by Spain's National Research Council (CSIC), set out on 15 December last year. Named after Alessandro Malaspina - who led a five-year survey of the Spanish empire's natural history, economy and geography in the late eighteenth century - the $€ 17$-million (US\$25-million) effort unites contributions from the Spanish
Ministry of Science and Innovation, the Spanish Navy and the BBVA Foundation, the charitable arm of the BBVA banking consortium.

Most oceanographic voyages are shorter than the Malaspina expedition (see 'Voyage of discovery'). By pouring resources into a single voyage, Malaspina's planners hoped to gather global data sets in a wide variety of research areas, from the distribution of persistent organic pollutants to the discovery and genetic characterization of deep-sea life. They also wanted to follow the progress of carbon from the atmosphere as it sinks through the sea, gets captured in the planktonic food chain and eventually comes to rest on the ocean floor. And the scale of the effort has helped to attract international collaborators. Carlos Duarte, a marine biologist at the Mediterranean Institute for Advanced Studies in Esporles who led the mission, says that the approach

was economical because loading instruments for one project costs less than changing instrumentation every month, as the research vessel would normally do.

"There are several other ocean exploration cruises going on, but Malaspina is a much more substantial scientific effort," says marine biologist Larry Madin, director of research at the Woods Hole Oceanographic Institution in Massachusetts, who is not involved in the expedition. For instance, the Atlantic Meridional Transect is a 16-year-old British project that is making comparable multidisciplinary observations, but is restricted to the Atlantic.

DNATURE.COM For more from the Malaspina cruise, see: go.nature.com/dwlq2w
The few cruises with a global reach are mainly sailing boats, such as Craig Venter's Sorcerer II Expedition or the French Tara Oceans expedition, 